before returning to the USA to become Assistant Professor of Zoology at Nebraska: "were it not for that unrivalled collection of living waterfowl the present work could not have been written'.

Unlike Paul Johnsgard, very few of us can be experts in so wide a field. This is a book which will be of the greatest value to all who take an interest in waterfowl, specialist and non-specialist alike.

JEFFERY HARRISON

\title{
Bird Navigation by G. V. T. Matthews. Cambridge UP, £2 cloth (15s. paperback).
}

This new edition of a book published in 1955 contains 350 references to more recent literature, and the text has been completely rewritten; the result is "virtually a new book'. As before, it is a compact, lucid and authoritative presentation of a fascinating subject, to which the author's own experiments have made a valuable contribution.

Dr Matthews restricts the term 'navigation' to 'the ability to initiate and maintain directed movement independently of landmarks'. He opens by setting the problem in its context of field observations, including the use of such techniques as ringing and radar. The experimental evidence for the existence of bearing-and-distance navigation is then considered, with a summary of the results of translocation of migrants; and next the physical bases of one-direction navigation, by day and by night. A review of homing experiments follows.

Chapters 7-11 deal with theoretical explanations and with experiments designed to test these. There are theories of sensory contact with home and of inertial navigation; and theories of navigation by geophysical grids, astronomical grids, and a grid derived from the sun's co-ordinates. Two final chapters usefully discuss the limitations of the avian eye and considerations involved in 'blind" flying and perception of gravity, in the appreciation of time intervals, and in circadian rhythms. All in all, it is a satisfying exposition which leaves the reader poised in expectation of still further advances from the active work continuing in various countries.

\section{A. LANDSBOROUGH THOMSON}

\section{Eagles, Hawks and Falcons of the World by Leslie Brown and Dean Amadon. Two vols. Country Life, 15 gns.}

These long-awaited volumes arrived on my desk shortly after returning from East Africa, where I had seen several birds of prey in puzzling plumages. They immediately proved their worth by illustrating a very striking pale form of the tawny eagle, which $I$ have so far been unable to find in any other book. Visitors to East Africa will need no reminding of the headaches encountered in trying to separate tawny, steppe and some other large eagles, with their varied plumages, from the limited range of readily available illustrations. Leslie Brown has studied eagles and other birds of prey, in his native Scotland, during many years in Africa, and in his other wanderings from India to Trinidad; this book contains the fruits of long years in the field. And there can be few ornithologists who have been able to study the breeding habits of the crowned hawk-eagle from their sitting-room window, as he still can from his house at Karen near Nairobi.

But for the misfortune of a considerably inferior book appearing not long ago entitled Birds of Prey of the World, that would have been the appropriate title for this massive and authoritative work, which will surely remain the standard 